\title{
Evaluation of Nonpathogenic Fusarium oxysporum and Pseudomonas fluorescens for Panama Disease Control
}

A. Belgrove, Agricultural Research Council-Grain Crops Institute, Potchefstroom 2520, South Africa, and Department of Microbiology and Plant Pathology, Forestry and Agricultural Biotechnology Institute, University of Pretoria, Pretoria 0002, South Africa; C. Steinberg, INRA-Université de Bourgogne, Microbiology of Soil and Environment, Dijon, France; and A. Viljoen, Department of Plant Pathology, University of Stellenbosch, Matieland 7602, South Africa

\begin{abstract}
Belgrove, A., Steinberg, C., and Viljoen, A. 2011. Evaluation of nonpathogenic Fusarium oxysporum and Pseudomonas fluorescens for Panama disease control. Plant Dis. 95:951-959.

Nonpathogenic Fusarium oxysporum endophytes from healthy banana roots were evaluated for their ability to reduce Fusarium wilt of banana (Panama disease). Isolates were identified morphologically and by using species-specific primers. Pathogenicity was confirmed by inoculating banana plantlets in the greenhouse. Nonpathogenic $F$. oxysporum isolates were grouped into 14 haplotype groups by polymerase chain reaction restriction fragment length polymorphism analysis of the intergenic spacer region, and representative isolates evaluated for biocontrol of $F$. oxysporum f. sp. cubense. In the greenhouse, 10 nonpathogenic $F$. oxysporum isolates were able to significantly reduce Fusarium wilt of banana. The isolate that protected banana plantlets best in the

greenhouse, a nonpathogenic $F$. oxysporum from the root rhizosphere, and Pseudomonas fluorescens WCS 417 were then field tested. When the putative biological control organisms were tested in the field, neither the nonpathogenic $F$. oxysporum, $P$. fluorescens, nor combinations thereof reduced Fusarium wilt development significantly. A number of factors could contribute to the lack of field protection, including soil microbial and chemical composition and reduced survival of biocontrol organisms in banana roots. A lack of knowledge regarding the etiology of Fusarium wilt of 'Cavendish' banana in the subtropics and the effect of $F$. oxysporum f. sp. cubense race and banana cultivar in protection of banana by biocontrol organisms should be further investigated.
\end{abstract}

Fusarium wilt, commonly known as Panama disease, is considered one of the most destructive diseases of banana. The disease was first discovered in 1876 and, by 1950, the Fusarium wilt pathogen Fusarium oxysporum f. sp. cubense (E.F. Sm.) W.C. Snyder \& H.N. Hansen had been disseminated to most banana-growing countries of the world (50). By 1960, F. oxysporum f. sp. cubense race 1 had almost destroyed the banana export industry in Central America that was entirely based on the highly susceptible 'Gros Michel' banana. Only the conversion to resistant 'Cavendish' cultivars saved the export industry from complete collapse (39). Soon thereafter, $F$. oxysporum f. sp. cubense race 4 was reported to attack Cavendish banana in the subtropics and later in tropical Asia $(39,56)$. The F. oxysporum f. sp. cubense strains that caused disease of Cavendish banana in the subtropics were referred to as $F$. oxysporum f. sp. cubense "subtropical" race 4, while those attacking Cavendish banana in the tropics were referred to as $F$. oxysporum $\mathrm{f}$. sp. cubense "tropical" race 4. F. oxysporum f. sp. cubense tropical and subtropical race 4 strains belong to different vegetative compatibility groups (VCGs), with VCG 01213/16 representing $F$. oxysporum $\mathrm{f}$. sp. cubense tropical and VCG 0120 F. oxysporum $\mathrm{f}$. sp. cubense subtropical race 4 (21). VCG 0120 causes disease to Cavendish banana in the subtropics following predisposition by cold winter temperatures and does not attack Cavendish banana in the tropics. F. oxysporum f. sp. cubense tropical race 4, however, causes disease to Cavendish banana in both the tropics and subtropics (39).

In South Africa, F. oxysporum f. sp. cubense subtropical race 4 is a major threat to the local banana industry that consists entirely of Cavendish banana cultivars $(56,57)$. Similarly, Cavendish banana crops in several Asian countries are seriously threatened by $F$. $o x$ -

Corresponding author: A. Viljoen, E-mail: altus@sun.ac.za

Accepted for publication 4 March 2011.

doi:10.1094/PDIS-06-10-0409

(C) 2011 The American Phytopathological Society ysporum f. sp. cubense tropical race 4 (39). No effective control measure is known for Fusarium wilt apart from preventing the introduction of the pathogen into banana fields and the use of disease-resistant plants. When these approaches are not feasible (for instance, when the pathogen is already present in fields and when no resistant dessert banana are available to replace Cavendish cultivars), alternative and unconventional disease management strategies have to be considered. One such alternative is biological control using fungal endophytes, a disease management strategy that provides an opportunity to control soilborne diseases of agricultural crops in an environmentally friendly way $(58,89)$.

In some agricultural soils, the incidence of Fusarium wilt is reduced despite the presence of a susceptible host, virulent pathogen, and favorable environmental conditions. Such soils are known as Fusarium wilt suppressive (50), and their suppressiveness can be attributed to various factors, both biotic and abiotic $(14,31,48)$. Suppression of Fusarium wilt diseases is primarily a function of the bacteria, actinomycetes, and fungi found in suppressive soils (3). Of these, nonpathogenic isolates of $F$. oxysporum and fluorescent Pseudomonas spp. are most frequently associated with Fusarium wilt suppression $(2,16,44)$. Preliminary field tests with nonpathogenic isolates of $F$. oxysporum and $F$. solani on tomato seedlings showed that Fusarium wilt of tomato can be suppressed by 50 to $80 \%$ (28) and under a variety of environmental conditions (29). Nonpathogenic strains of $F$. oxysporum have also been used to effectively control Fusarium wilt of sweet potato, caused by $F$. oxysporum f. sp. batatas, in the field when applied to cuttings (47). The bacterial isolate Pseudomonas fluorescens WCS 417 has reduced the incidence of Fusarium wilt of banana in greenhouse inoculation studies by $87.4 \%$ (35). P. fluorescens WCS $417 \mathrm{r}$ was also able to induce resistance against Fusarium wilt pathogens of carnation (55) and tomato (15).

Not many studies investigated the effect of soil chemical and physical conditions on Fusarium wilt of banana. Peng et al. (38) reported that soil edaphic properties such as $\mathrm{Ca}$ and $\mathrm{Fe}$ content, temperature, and water content affected chlamydospore germination and Fusarium wilt severity in banana plants under greenhouse conditions, while Domínguez et al. (14) demonstrated that struc- 
tural stability of soil aggregates differ in soils conducive and suppressive to Fusarium wilt of banana. In his monograph on Fusarium wilt in Central America, Stover $(50,51)$ indicated that soil $\mathrm{pH}$ and $\mathrm{Ca}$ content of soils were responsible for the suppression of Panama disease in the field, and that $\mathrm{NH}_{4}$ fertilizer enhances the development of the disease.

Nonpathogenic isolates of $F$. oxysporum in suppressive soils can be found either in the root rhizosphere or as endophytes inside symptomless banana roots $(23,28)$. Forsyth et al. (20) and Gerlach et al. (23) demonstrated that nonpathogenic $F$. oxysporum endophytes significantly decreased Fusarium wilt of banana plants in greenhouse trials, and Nel et al. (35) demonstrated the same for nonpathogenic $F$. oxysporum isolates from the banana root rhizosphere. The mechanism of induced systemic resistance was proposed for protection by nonpathogenic $F$. oxysporum $(23,46)$. In addition, competition for nutrients (4) and infection sites (45) was proposed for other Fusarium wilt diseases. Thangavelu and Jayanthi (53) were the first to report the successful field application of nonpathogenic $F$. oxysporum to reduce Fusarium wilt of banana in India. In their study, the biocontrol agent targeted $F$. oxysporum $\mathrm{f}$. sp. cubense race 1 infection of 'Rasthali' banana and reduced disease severity by $80 \%$. In a similar study in Malaysia, however, nonpathogenic $F$. oxysporum endophytes were unable to provide protection of 'Pisang berangan' banana against $F$. oxysporum f. sp. cubense race 4 in the field (54).

Nonpathogenic strains of $F$. oxysporum cannot be distinguished from pathogenic strains by means of traditional agar plating techniques and comparison of morphological characters, nor can formae speciales be detected by using molecular markers $(8,21)$. This is because formae speciales of $F$. oxysporum are not monophyletic, as is evident from phylogenetic trees where isolates representing different formae speciales and nonpathogenic isolates grouped together rather than with representatives from the same forma specialis. Host specificity, therefore, is required to classify pathogenic strains into one of approximately 120 formae speciales, and cultivar specificity to further divide these formae speciales into races (7). Polymerase chain reaction (PCR)-restriction fragment length polymorphism (RFLP) analysis of the ribosomal (r)DNA is useful for differentiating closely related strains within $F$. oxysporum and to estimate the genetic relatedness between these groups $(17,18)$. The sequences of the intergenic spacer (IGS) region have also been used for RFLP analysis of pathogenic and nonpathogenic strains of F. oxysporum (6).

The aim of this study was to identify an effective biocontrol strain of $F$. oxysporum from disease-suppressive fields to use for field protection of banana plants against Fusarium wilt. Therefore, nonpathogenic $F$. oxysporum endophytes were isolated from banana roots in Fusarium wilt-suppressive soils in the Kiepersol area of South Africa, their genetic relatedness determined by means of PCR-RFLP analysis of the IGS region, and their potential as biological control organisms of Fusarium wilt of banana evaluated in the greenhouse. The most promising nonpathogen was then tested for protection of Cavendish banana plants against $F$. oxysporum $\mathrm{f}$. sp. cubense in the field, along with a nonpathogenic F. oxysporum isolate from the banana root rhizosphere and P. fluorescens WCS 417, a well-known suppressor of Fusarium wilt diseases $(30,42)$. The latter two organisms were identified by Nel et al. (35) as potential biocontrol candidates against $F$. oxysporum f. sp. cubense.

\section{Materials and Methods}

Isolation and identification of isolates. Fungal endophytes were isolated from the roots of 10 symptomless Cavendish banana plants grown from micropropagated plants (DuRoi Laboratories, Letsitele, South Africa) in Kiepersol, South Africa. Three plants each were selected from three field sites considered to be disease suppressive, designated sites A, B, and C. All three of these sites were free of Fusarium wilt symptoms, despite being surrounded by banana plants severely affected by the disease. From each of the three sites, 10 soil samples were collected for nutrient analyses at the Department of Plant Production, University of Pretoria (Table 1). A 10th healthy plant was selected inside a small hothouse structure ( $3 \mathrm{~m}$ long by $3 \mathrm{~m}$ wide by $5 \mathrm{~m}$ high) built to cover 10 banana plants near a farmstead; however, this site was not considered disease suppressive (designated site D). From each banana plant, five roots were randomly sampled. The roots were washed in the field to remove all excess dirt, and transported in McCartney bottles placed on ice to the laboratories at the Forestry and Agricultural Biotechnology Institute, University of Pretoria, Pretoria.

At the laboratory, the roots were cleaned of any remaining soil by first washing them with sterile water. The roots were then surface sterilized with $75 \%$ ethanol for $1 \mathrm{~min}, 1 \%$ sodium hypochloride for $3 \mathrm{~min}$, and $95 \%$ ethanol for $30 \mathrm{~s}$. Each root was cut into smaller pieces, and five pieces of the same root were placed apart from each other onto modified Komada medium in the same petri dish (26). The petri dishes were incubated at $25^{\circ} \mathrm{C}$ and checked daily for fungal growth. Once colonies of Fusarium spp. developed sufficiently, single-spore isolates were prepared (37) and plated onto half-strength potato dextrose agar (PDA; Difco Laboratories, Detroit) containing Novobiocin (Sigma-Aldrich, St. Louis) at 0.02 $\mathrm{g} \mathrm{liter}^{-1}$. Isolates obtained from each banana plant were then preserved in $15 \%$ glycerol, freeze dried, and maintained in the culture collection at the Department of Plant Pathology, Stellenbosch University, South Africa.

All Fusarium isolates were plated onto PDA and carnation leaf agar (CLA) (20 g of Biolab agar, 1,000 $\mathrm{ml}$ of $\mathrm{H}_{2} \mathrm{O}$, and one or two 5 -mm sterilized carnation leaves) for cultural and morphological identification, respectively. $F$. oxysporum was identified to species level based on morphology of microconidia, macroconidia, conidiophores, and chlamydospores (37). When uncertain about their morphological species identity, Fusarium isolates were subjected to molecular identification using $F$. oxysporum-specific primers FOF1 (5'-ACA TAC CAC TTG TTG CCT CG-3') and FOR1 (5'CGC CAA TCA ATT TGA GGA ACG-3') (33).

Characterization of $\boldsymbol{F}$. oxysporum isolates. Isolates of $F$. oxysporum were separated into haplotypes using PCR-RFLP analysis as described by $\mathrm{Nel}$ et al. (34). DNA was first extracted from all the

Table 1. Soil nutrient status of three Fusarium wilt-suppressive sites (sites A, B, and C) and an experimental field site in Kiepersol, South Africa

\begin{tabular}{|c|c|c|c|c|c|}
\hline \multirow[b]{2}{*}{$\underline{\text { Parameter }}$} & \multirow[b]{2}{*}{$P$ value } & \multicolumn{4}{|c|}{ Soil site ${ }^{\mathrm{z}}$} \\
\hline & & $\begin{array}{c}\text { Site A } \\
(-25.079681,31.017784)\end{array}$ & $\begin{array}{c}\text { Site B } \\
(-25.090188,31.019471)\end{array}$ & $\begin{array}{c}\text { Site C } \\
(-25.113206,31.03671)\end{array}$ & $\begin{array}{c}\text { Field trial site } \\
(-25.079837,31.0418)\end{array}$ \\
\hline $\mathrm{Ca}\left(\mathrm{cmol}_{\mathrm{c}} / \mathrm{kg}\right)$ & 0.9877 & $3.3329 \pm 0.6848 \mathrm{a}$ & $3.2616 \pm 0.9089 a$ & $3.3065 \pm 2.1121 \mathrm{a}$ & $3.4543 \pm 0.6971 \mathrm{a}$ \\
\hline $\mathrm{Fe}(\mathrm{mg} / \mathrm{kg})$ & 0.0000 & $141.752 \pm 22.3756 b$ & $84.716 \pm 14.7878 a$ & $141.752 \pm 22.3756 b$ & Not measured \\
\hline $\mathrm{K}\left(\mathrm{cmol}_{\mathrm{c}} / \mathrm{kg}\right)$ & 0.0000 & $0.4398 \pm 0.2139 a$ & $0.5483 \pm 0.1657 \mathrm{a}$ & $0.4287 \pm 0.1970 \mathrm{a}$ & $1.9947 \pm 0.7281 \mathrm{~b}$ \\
\hline $\mathrm{Mg}\left(\mathrm{cmol}_{\mathrm{c}} / \mathrm{kg}\right)$ & 0.0253 & $1.0451 \pm 0.1399 \mathrm{a}$ & $0.9800 \pm 0.5078 \mathrm{a}$ & $1.0063 \pm 0.4485 \mathrm{a}$ & $1.4546 \pm 0.3059 \mathrm{~b}$ \\
\hline $\mathrm{Na}\left(\mathrm{cmol}_{\mathrm{c}} / \mathrm{kg}\right)$ & 0.0066 & $0.1501 \pm 0.1715 \mathrm{ab}$ & $0.2697 \pm 0.0428 \mathrm{c}$ & $0.2397 \pm 0.0993 b c$ & $0.1217 \pm 0.0245 \mathrm{a}$ \\
\hline $\mathrm{NH}_{4}{ }^{+}\left(\mathrm{cmol}_{\mathrm{c}} / \mathrm{kg}\right)$ & 0.0777 & $0.0855 \pm 0.0406 \mathrm{a}$ & $0.0855 \pm 0.5157 \mathrm{a}$ & $0.0968 \pm 0.0406 \mathrm{ab}$ & $0.1396 \pm 0.0689 \mathrm{~b}$ \\
\hline $\mathrm{NO}_{3}^{-}\left(\mathrm{cmol}_{\mathrm{c}} / \mathrm{kg}\right)$ & 0.0000 & $0.0568 \pm 0.0189 a$ & $0.0614 \pm 0.0319 \mathrm{a}$ & $0.05678 \pm 0.0189 \mathrm{a}$ & $0.0197 \pm 0.0937 \mathrm{~b}$ \\
\hline $\mathrm{P}(\mathrm{mg} / \mathrm{kg})$ & 0.0000 & $12.54 \pm 5.5828 \mathrm{a}$ & $50.52 \pm 27.0197 \mathrm{~b}$ & $75.12 \pm 22.6026 \mathrm{c}$ & $50.1 \pm 18.4858 \mathrm{~b}$ \\
\hline $\mathrm{pH}\left(\mathrm{H}_{2} \mathrm{O}\right)\left(\mathrm{cmol}_{\mathrm{c}} / \mathrm{kg}\right)$ & 0.0000 & $6.307 \pm 0.4078 \mathrm{c}$ & $4.908 \pm 0.4726 \mathrm{a}$ & $4.730 \pm 0.4856 \mathrm{a}$ & $5.835 \pm 0.2539 \mathrm{~b}$ \\
\hline
\end{tabular}

${ }^{\mathrm{z}}$ Mean of 10 soil samples per site. The same letter within columns indicates no significant difference at $P<0.05$ using one-way analysis of variance (Statgraphics version 5.0). 
F. oxysporum isolates using the method of Sambrook et al. (43). The IGS region of each isolate was then amplified using the primer set PNFo (5'-CCCGCCTGGCTGCGTCCGACTC-3') and PN22 (5'-CAAGCATATGACTACTGGC-3') (17). Five restriction enzymes were used to digest the PCR product, including $M s p \mathrm{I}, R s a \mathrm{I}$, HaeIII, HinfI and ScrFI (Roche Molecular Biochemicals, Mannheim, Germany). These enzymes ( $2 \mathrm{U}$ ) were added to $10 \mu \mathrm{l}$ of each PCR product in separate $20-\mu \mathrm{l}$ reaction mixtures at $37^{\circ} \mathrm{C}$ for $4 \mathrm{~h}$. The enzyme-digested DNA fragments were analyzed on a 3 to $4 \%$ agarose gel, stained with ethidium bromide, and viewed under the UV light.

To distinguish pathogenic from nonpathogenic isolates, all the $F$. oxysporum isolates were tested for their pathogenicity to $10-\mathrm{cm}$ Cavendish banana plantlets obtained from DuRoi Laboratories. The banana plantlets were first replanted into 250-ml plastic cups and inoculated by following the method described by Nel et al. $(34,35)$. Two sets of control plants were included in the trial. One set received water only and the other set was inoculated with $F$. oxysporum f. sp. cubense CAV 092, a highly virulent isolate of $F$. oxysporum f. sp. cubense subtropical race 4 isolated from diseased Cavendish banana in Kiepersol, South Africa (57), at a final spore concentration of $1 \times 10^{5}$ spores $/ \mathrm{ml}$. Six replicate plants were used for each treatment, and the trial was repeated three times. After 3 to 4 weeks, the rhizomes of all the plants were cut open to see whether internal symptoms, which can be recognized as a yellow to reddish discoloration of the inner rhizome tissue, developed. Severity of symptoms was then rated according to the INIBAP rating scale for Fusarium wilt of banana (10). Once the disease developed in banana plantlets, the pathogen was reisolated from $50 \%$ of the diseased rhizomes to complete Koch's postulates.

Biological control of $\boldsymbol{F}$. oxysporum f. sp. cubense. Greenhouse testing. Seventeen isolates of $F$. oxysporum, representative of all PCR-RFLP haplotypes generated in this study, were evaluated in pot trials in the greenhouse as potential biological control organisms of $F$. oxysporum f. sp. cubense. Tissue cultures $(10 \mathrm{~cm})$ of Cavendish banana plants obtained from DuRoi Laboratories were first planted into 250-ml plastic cups and their roots slightly compressed as described previously. The roots were then inoculated with putative biological control isolates grown in Armstrong Fusarium medium (9) at a final concentration of $1 \times 10^{5}$ conidia $\mathrm{ml}^{-1}$ by adding $25 \mathrm{ml}$ of a $1 \times 10^{6}$ spores $\mathrm{ml}^{-1}$ suspension to the plastic cup (35). Before inoculation, the $F$. oxysporum spores were washed three times with sterile distilled water.

After 1 week, endophyte-inoculated plants were replanted to pots filled with $500 \mathrm{~g}$ of $F$. oxysporum f. sp. cubense-infested soil (35). The F. oxysporum f. sp. cubense isolate used (CAV 092) was established in this soil by first cultivating it on millet seed (49), and then mixing the pathogen-colonized millet seed with sandy soil to a $3 \%$ concentration (wt/wt). Control plants were not treated with any potential biocontrol agent and were planted in both $F$. oxysporum $\mathrm{f}$. sp. cubense-infested and uninfested soil. For each nonpathogenic $F$. oxysporum isolate, six replicate plants were used, and the experiment was repeated three times. The banana plants received $12 \mathrm{~h}$ of illumination daily at a temperature of $28^{\circ} \mathrm{C}$, while the temperature in the dark was set at $20^{\circ} \mathrm{C}$. After 7 weeks, the plants were uprooted and cut open, and symptoms were rated according to the INIBAP rating scale for Fusarium wilt of banana (10).

Field testing. Three candidate microorganisms were selected for field evaluation of biological control of Fusarium wilt of banana. These included the nonpathogenic F. oxysporum isolate that suppressed Fusarium wilt best during greenhouse evaluation in the current study (CAV 553), a nonpathogenic $F$. oxysporum isolated from the banana root rhizosphere by Nel et al. (36) (CAV 255), and P. fluorescens WCS 417, provided by Prof. L. C. van Loon (University of Utrecht, The Netherlands). Both $F$. oxysporum isolates were grown in Armstrong Fusarium medium (9) at $25^{\circ} \mathrm{C}$ for 7 days, and the P. fluorescens isolate was grown on Pseudomonasselective agar at $37^{\circ} \mathrm{C}$ in the dark for 2 days (25). After 7 days, conidia of the $F$. oxysporum isolates were harvested by filtering through cheesecloth and centrifugation at $5,000 \times g$ at $15^{\circ} \mathrm{C}$ for 20 min. The spores were then washed three times in sterile distilled water and adjusted to a final concentration of $1 \times 10^{6}$ spores $\mathrm{ml}^{-1}$. The bacteria were also scraped from the Pseudomonas selective medium, suspended in sterile distilled water, and adjusted to a final cell concentration of $1 \times 10^{8} \mathrm{CFU} \mathrm{ml}^{-1}$.

Field-ready $(20-\mathrm{cm})$ pathogen-free tissue cultures of Cavendish banana plantlets from DuRoi Laboratories were treated with the putative biological control organisms 1 week before planting. Four different treatments were used, which included the three different organisms separately and in combination. For the combination treatment, the three individual spore suspensions were mixed together in equal volumes. The roots of plants were inoculated by drenching the planting medium around the pseudostem of each plant with a $100-\mathrm{ml}$ suspension of fungal conidia or bacterial CFU. The roots of plants were also dipped into the respective fungal spore and bacterial cell suspensions immediately before planting. Two control treatments were included in the field trial. The first control consisted of a root drench with propiconazole (Tilt) at a concentration of $25 \mathrm{ppm}$ (a.i.). Propiconazole has previously been shown to reduce the incidence of $F$. oxysporum f. sp. cubense in vitro and Fusarium wilt of banana in the greenhouse by $75 \%$ (36). The second control consisted of water obtained at the banana field. Each treatment was applied to 30 plants, which were divided into three groups (blocks) of 10 plants each. The treatment blocks were then planted in a completely randomized block design in a field site naturally infested with $F$. oxysporum f. sp. cubense subtropical race 4 (57). Guard rows were planted between the blocks to prevent cross-contamination by the putative biocontrol agents upon root contact between plants.

The trial was conducted at a site considered to be one of the more severe Panama disease-infected areas near Kiepersol in South Africa, with regular losses of newly planted Cavendish banana plantlets in access of $70 \%$ (A. Viljoen, unpublished data), and was at least $3 \mathrm{~km}$ away from the sites where the putative biocontrol isolates were collected. The trial site was managed according to standard farmer practices. Before planting, the nutrient status of the field was determined by randomly collecting 10 soil samples in the trial site for analyses at the Department of Plant Production, University of Pretoria. The field was then planted at a density of 1,800 plants/ha, with $3 \mathrm{~m}$ between rows and $1.8 \mathrm{~m}$ within rows. Holes for the new plants (approximately 30 by 30 by $40 \mathrm{~cm}$ ) were dug between the remains of banana plants from a previous banana plantation. Because of the high levels of $\mathrm{K}, \mathrm{Mg}$, and $\mathrm{NO}_{3}$ at the site (Table 1), the regular application of $20 \mathrm{~g}$ of limestone ammonium nitrate with $20 \mathrm{~g}$ potassium chloride per mat every 2 weeks was withheld but the irrigation regime was retained. No chemicals were applied for pests and diseases, and weeds were removed with shovels. The plants were maintained using standard desuckering and leaf-trimming practices. Plants were evaluated for external symptom development on a monthly basis, beginning 3 months after planting. Plants that were clearly affected by Fusarium wilt were recorded as diseased and marked for future reference.

Statistical analysis. Statistical analysis was conducted using Statgraphics 5 Plus $^{26}$ (Manugistics Inc., Rockville, MD). The experiments were analyzed using multifactor analysis of variance and means were separated using Fisher's least significant difference. Significance were evaluated at $P \leq 0.05$ for all tests. The data of the in vivo biological control testing were pooled for the three repeat experiments if the experiment-treatment interaction was not significant.

\section{Results}

Isolation and identification of isolates. Endophytic fungi were isolated from the roots of all banana plants collected at the three suppressive soil sites and in the hothouse in Kiepersol. These isolates included not only species of Fusarium but also of known mycoparasites such as Trichoderma and Gliocladium spp. In total, 70 isolates of Fusarium were collected based on colony color and spore morphology, of which 43 isolates were identified as $F$. oxysporum (Table 2). When uncertain, the amplification of a single 
340-bp PCR fragment using $F$. oxysporum-specific primers confirmed the isolates' identity. Isolates identified as other Fusarium spp. did not produce this fragment. In all, 7 F. oxysporum isolates were obtained from site A, 20 from site B, 12 from site C, and 4 from site D. Six of the F. oxysporum isolates proved to be pathogenic to banana: five from site B and one from site D. Only isolates of $F$. oxysporum that proved to be nonpathogenic to banana were selected for further biological studies.

Table 2. Pathogenicity and intergenic spacer region (IGS) haplotype, obtained by means of restriction fragment length polymorphism analysis, of Fusarium oxysporum isolates collected from healthy banana roots in Fusarium wilt-suppressive soils in South Africa

\begin{tabular}{|c|c|c|c|c|c|c|c|}
\hline \multirow[b]{2}{*}{ Group, strainv } & \multirow[b]{2}{*}{ Origin } & \multirow[b]{2}{*}{ Pathogenicity } & \multicolumn{5}{|c|}{ IGS haplotype $^{u}$} \\
\hline & & & MspI & RsaI & HaeIII & HinfI & ScrFI \\
\hline \multicolumn{8}{|l|}{1} \\
\hline CAV $526^{\mathrm{w}}$ & Kiepersol, Site A, plant 1 & Nonpathogen & A & A & A & A & A \\
\hline \multicolumn{8}{|c|}{ 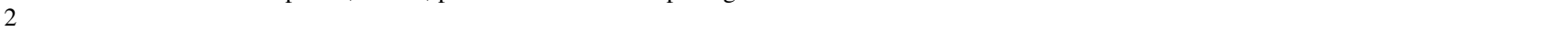 } \\
\hline CAV 527 & Kiepersol, Site A, plant 1 & Nonpathogen & A & $\mathrm{B}$ & $\mathrm{E}$ & B & A \\
\hline CAV $551^{w}$ & Kiepersol, Site C, plant 1 & Nonpathogen & A & B & $\mathrm{E}$ & B & A \\
\hline CAV 564 & Kiepersol, Site D, plant 5 & Nonpathogen & A & B & $\mathrm{E}$ & B & A \\
\hline \multicolumn{8}{|c|}{1} \\
\hline CAV 529 & Kiepersol, Site A, plant1 & Nonpathogen & A & $\mathrm{C}$ & A & B & A \\
\hline CAV 531w & Kiepersol, Site A, plant 3 & Nonpathogen & A & $\mathrm{C}$ & A & B & A \\
\hline CAV 532 & Kiepersol, Site A, plant 3 & Nonpathogen & A & $\mathrm{C}$ & A & B & A \\
\hline CAV 533 & Kiepersol, Site B, plant 1 & Nonpathogen & A & $\mathrm{C}$ & A & B & A \\
\hline CAV $535^{\mathrm{w}}$ & Kiepersol, Site B, plant 1 & Nonpathogen & A & $\mathrm{C}$ & A & B & A \\
\hline CAV 560 & Kiepersol, Site C, plant 3 & Nonpathogen & A & $\mathrm{C}$ & A & B & A \\
\hline \multicolumn{8}{|c|}{ 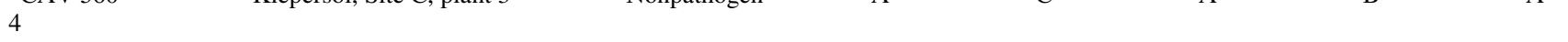 } \\
\hline CAV 536 & Kiepersol, Site B, plant 1 & Nonpathogen & A & $\mathrm{C}$ & A & B & B \\
\hline CAV $563^{w}$ & Kiepersol, Site D, plant 1 & Nonpathogen & A & $\mathrm{C}$ & A & B & B \\
\hline CAV $565^{w}$ & Kiepersol, Site D, plant 1 & Nonpathogen & A & $\mathrm{C}$ & A & $\mathrm{B}$ & $\mathrm{B}$ \\
\hline \multicolumn{8}{|c|}{ 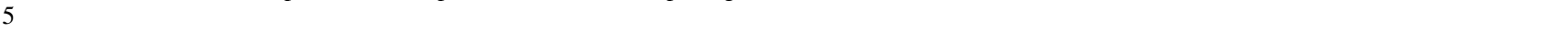 } \\
\hline CAV $566^{w}$ & Kiepersol, Site D, plant 1 & Nonpathogen & A & $\mathrm{C}$ & A & $\mathrm{C}$ & A \\
\hline \multicolumn{8}{|c|}{1} \\
\hline CAV 530 & Kiepersol, Site A, plant 1 & Nonpathogen & A & $\mathrm{C}$ & $\mathrm{C}$ & B & A \\
\hline CAV 534 & Kiepersol, Site B, plant 1 & Nonpathogen & A & $\mathrm{C}$ & $\mathrm{C}$ & B & A \\
\hline CAV 537w & Kiepersol, Site B, plant 1 & Nonpathogen & A & $\mathrm{C}$ & $\mathrm{C}$ & B & A \\
\hline CAV 540 & Kiepersol, Site B, plant 1 & Nonpathogen & A & $\mathrm{C}$ & $\mathrm{C}$ & B & A \\
\hline CAV 545 & Kiepersol, Site B, plant 2 & Nonpathogen & A & $\mathrm{C}$ & $\mathrm{C}$ & B & A \\
\hline CAV $557^{\mathrm{w}}$ & Kiepersol, Site C, plant 3 & Nonpathogen & A & $\mathrm{C}$ & $\mathrm{C}$ & B & A \\
\hline CAV 558 & Kiepersol, Site C, plant 3 & Nonpathogen & A & $\mathrm{C}$ & $\mathrm{C}$ & B & A \\
\hline \multicolumn{8}{|c|}{ (2) } \\
\hline CAV 554 & Kiepersol, Site C, plant 2 & Nonpathogen & A & $\mathrm{C}$ & $\mathrm{D}$ & B & A \\
\hline CAV $555^{\mathrm{w}}$ & Kiepersol, Site C, plant 3 & Nonpathogen & A & $\mathrm{C}$ & $\mathrm{D}$ & B & A \\
\hline CAV 556 & Kiepersol, Site C, plant 3 & Nonpathogen & A & $\mathrm{C}$ & $\mathrm{D}$ & B & A \\
\hline CAV 548 & Kiepersol, Site B, plant 3 & Nonpathogen & A & $\mathrm{C}$ & $\mathrm{D}$ & B & A \\
\hline CAV 547 & Kiepersol, Site B, plant 3 & Nonpathogen & A & $\mathrm{C}$ & $\mathrm{D}$ & B & A \\
\hline CAV 562 & Kiepersol, Site C, plant 3 & Nonpathogen & A & $\mathrm{C}$ & $\mathrm{D}$ & $\mathrm{B}$ & A \\
\hline \multicolumn{8}{|c|}{ 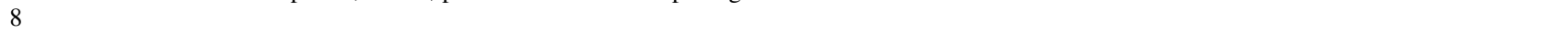 } \\
\hline CAV 538 & Kiepersol, Site B, plant 1 & Pathogen & A & $\mathrm{C}$ & $\mathrm{D}$ & $\mathrm{C}$ & $\mathrm{C}$ \\
\hline CAV 539 & Kiepersol, Site B, plant 1 & Pathogen & A & $\mathrm{C}$ & $\mathrm{D}$ & $\mathrm{C}$ & $\mathrm{C}$ \\
\hline CAV 542 & Kiepersol, Site B, plant 2 & Pathogen & A & $\mathrm{C}$ & $\mathrm{D}$ & $\mathrm{C}$ & $\mathrm{C}$ \\
\hline CAV 550 & Kiepersol, Site B, plant 3 & Pathogen & A & $\mathrm{C}$ & $\mathrm{D}$ & $\mathrm{C}$ & $\mathrm{C}$ \\
\hline CAV 635 & Kiepersol, Site D, plant 1 & Pathogen & A & $\mathrm{C}$ & $\mathrm{D}$ & $\mathrm{C}$ & $\mathrm{C}$ \\
\hline CAV 633 & Kiepersol, Site B, plant 1 & Pathogen & A & $\mathrm{C}$ & $\mathrm{D}$ & $\mathrm{C}$ & $\mathrm{C}$ \\
\hline \multicolumn{8}{|c|}{ A } \\
\hline CAV $552^{\mathrm{w}}$ & Kiepersol, Site C, plant 2 & Nonpathogen & A & $\mathrm{C}$ & A & A & A \\
\hline \multicolumn{8}{|c|}{ 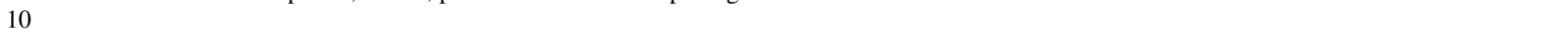 } \\
\hline CAV $559^{w}$ & Kiepersol, Site C, plant 3 & Nonpathogen & A & $\mathrm{D}$ & A & B & A \\
\hline 11 & & & & & & & \\
\hline CAV $528^{w}$ & Kiepersol, Site A, plant 1 & Nonpathogen & B & A & $\mathrm{B}$ & $\mathrm{E}$ & A \\
\hline CAV 549 & Kiepersol, Site B, plant 3 & Nonpathogen & $\mathrm{B}$ & A & B & $\mathrm{E}$ & A \\
\hline 12 & & & & & & & \\
\hline CAV $546^{\mathrm{w}}$ & Kiepersol, Site B, plant 3 & Nonpathogen & B & $\mathrm{C}$ & A & $\mathrm{D}$ & B \\
\hline 13 & & & & & & & \\
\hline CAV 541 & Kiepersol, Site B, plant 2 & Nonpathogen & $\mathrm{C}$ & A & A & A & A \\
\hline CAV $543^{\mathrm{w}}$ & Kiepersol, Site B, plant 2 & Nonpathogen & $\mathrm{C}$ & A & A & A & A \\
\hline CAV $544^{w}$ & Kiepersol, Site B, plant 2 & Nonpathogen & $\mathrm{C}$ & A & A & A & A \\
\hline CAV 561 & Kiepersol, Site C, plant 3 & Nonpathogen & $\mathrm{C}$ & A & A & A & A \\
\hline 14 & & & & & & & \\
\hline CAV $553^{w}$ & Kiepersol, Site C, plant 2 & Nonpathogen & $\mathrm{C}$ & A & A & B & A \\
\hline CAV $092^{x}$ & Kiepersol & Pathogen & $\ldots$ & $\ldots$ & $\ldots$ & $\ldots$ & $\ldots$ \\
\hline CAV $225^{y}$ & Kiepersol & Nonpathogen & $\ldots$ & $\ldots$ & $\ldots$ & $\ldots$ & $\ldots$ \\
\hline WCS $417^{z}$ & Wheat field, The Netherlands & $\ldots$ & $\ldots$ & $\ldots$ & $\ldots$ & $\ldots$ & $\ldots$ \\
\hline
\end{tabular}


Characterization of $\boldsymbol{F}$. oxysporum isolates. The primer set PNFo and PN22 amplified a single DNA fragment of approximately $1,700 \mathrm{bp}$ that represents the IGS region for all $43 \mathrm{~F}$. oxysporum isolates. When digested with restriction enzymes, a number of different banding patterns were produced. Three distinct RFLP fingerprinting patterns were recognized for $M s p \mathrm{I}$ and $S c r F I$, four for RsaI, and five for HinfI and HaeIII. A different alphabetical letter was assigned to each unique fragment pattern generated by a restriction enzyme and, according to these letters, each isolate was designated a five-letter code. The five-letter codes divided the 43 F. oxysporum isolates into 14 PCR-RFLP haplotype groups (Table 2). The largest IGS haplotype was ACCBA, which contained eight nonpathogenic $F$. oxysporum isolates from the three field sites A, B, and C. The $F$. oxysporum $\mathrm{f}$. sp. cubense isolate (CAV 092), that is known to be pathogenic to banana (56) grouped with six $F$. oxysporum isolates that proved to be pathogenic to banana in the IGS haplotype ACDCC.

Several IGS haplotypes were found at all the collection sites (Table 2). In site A, for instance, five haplotypes were present, while eight haplotypes were present in both sites B and C. In the hothouse, four haplotypes were found associated with the healthy roots of a single banana plant. Some haplotypes, such as ACABA and ACCBA, were found at all three field sites (A, B, and C), while four of the haplotypes were found at two of the field sites. Five groups were unique to the respective sites, three of which came from site $\mathrm{C}$. The number of haplotypes obtained from each plant differed substantially, even at the same collection site. For instance, five different haplotypes were obtained from the same plant in both sites $\mathrm{A}$ and $\mathrm{C}$ while, at the same sites, only one haplotype was found associated with another plant. Interestingly, all three plants colonized by nonpathogenic $F$. oxysporum endophytes in $\mathrm{C}$, as well as the single plant in site $\mathrm{D}$, were also colonized by $F$. oxysporum f. sp. cubense isolates.

Biological control of $\boldsymbol{F}$. oxysporum f. sp. cubense. Greenhouse testing. Fusarium wilt of banana was reduced in greenhouse trials by most of the nonpathogenic $F$. oxysporum isolates tested from disease-suppressive soils (Fig. 1). Ten isolates reduced the disease significantly $(P \leq 0.05)$. These isolates were found in sites B (CAV 535 and CAV 546), C (CAV 551, CAV 552, CAV 553, CAV 557, and CAV 559), and D (CAV 563, CAV 565, and CAV 566). The best results were obtained with isolates CAV 553, CAV 552, and CAV 563 that, when compared with the control treatment, reduced disease severity by $69.2,65.4$, and $57.7 \%$, respectively. Of these, CAV 553 was selected for field evaluation as a potential biocontrol agent of Panama disease of banana.

Field testing. Fusarium wilt in South Africa is known to develop optimally after predisposition to cold winter temperatures that occur from July to August. Thus, no symptoms were visible 6 months after planting in the trial (before winter). When the trial site was visited 6 months later (after winter), sufficient external symptoms developed for the trial to be rated. Visible symptoms included the yellowing of the lower leaves that later progressed to the younger leaves. Because Cavendish plants affected by Panama disease are known not to recover from the disease and eventually die, only the incidence of the disease was recorded.

No significant reduction in disease incidence was found among the various treatments. Slight reductions (between 5 and 14\%) in disease incidence, however, were observed in plants treated with the putative biocontrol agents when they were applied separately (Fig. 2), although they were not significant. Tilt, a product that was previously shown to reduce $F$. oxysporum f. sp. cubense in vitro and in the greenhouse, had no significant effect on Fusarium wilt in the field trial. The trial was allowed to continue for another year, when another rating was conducted. Still, the treatments did not significantly reduce Panama disease in the field (results not shown).

Soil nutrient composition. The amount of $\mathrm{Ca}, \mathrm{K}, \mathrm{Mg}, \mathrm{NO}_{3}$, and $\mathrm{NH}_{4}$ did not differ significantly among the three field sites considered to be suppressive to Fusarium wilt of banana (sites A, B, and

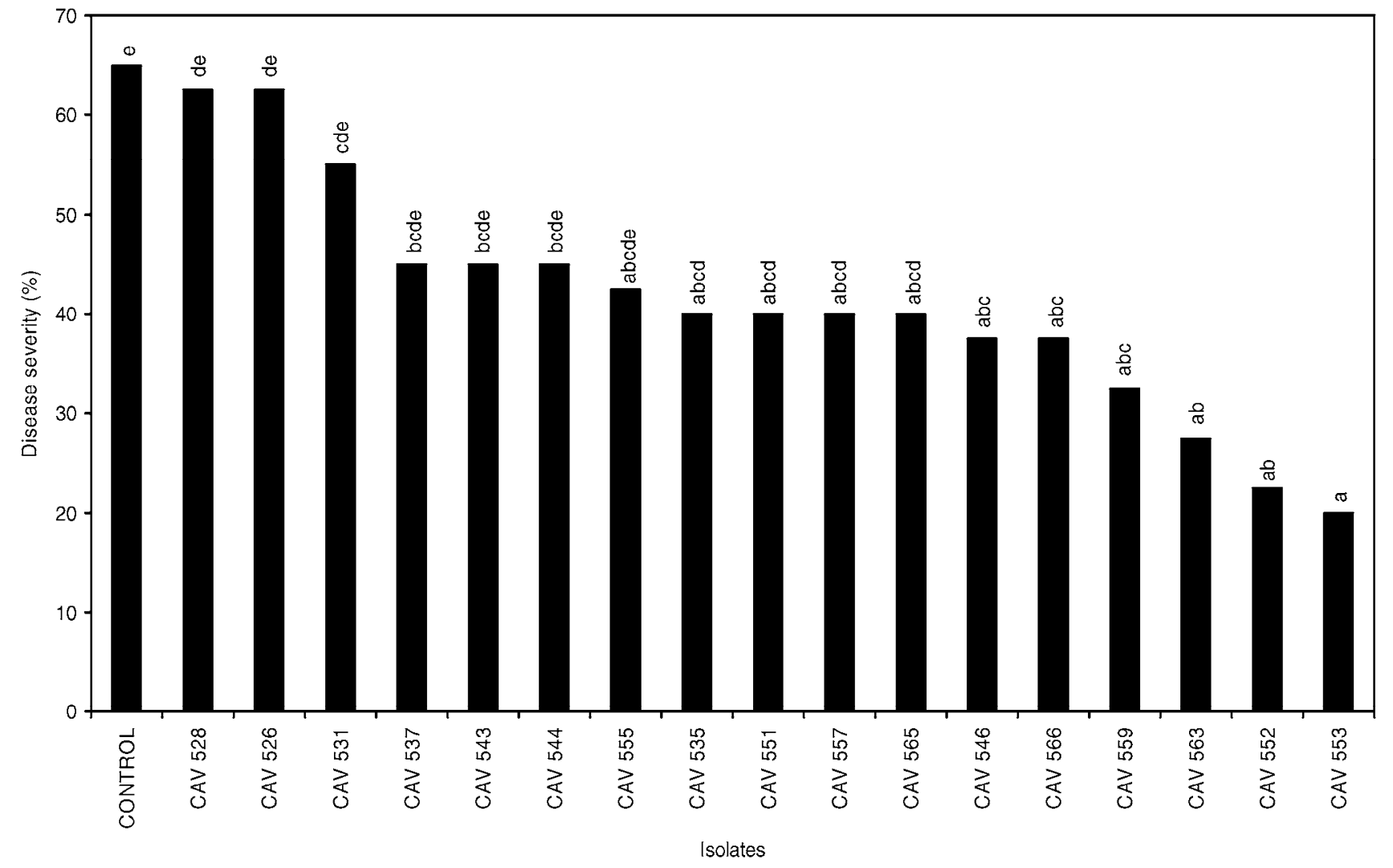

Fig. 1. Disease severity of Fusarium wilt of banana caused by Fusarium oxysporum f. sp. cubense in the greenhouse following treatment with nonpathogenic $F$. oxysporum endophytes. The banana plants were planted in $F$. oxysporum f. sp. cubense (CAV 092)-infested soil a week after treatment with $F$. oxysporum isolates nonpathogenic to banana. The control application was treated with the pathogenic isolate CAV 092 only. Bars presented with the same letter are not significantly different at $P \leq 0.05$ using Fisher's least significant difference. 
C; Table 1). Site D was not considered to be potentially disease suppressive, as explained earlier; therefore, soil analysis for this site was not performed. Significantly more $\mathrm{K}, \mathrm{Mg}$, and $\mathrm{NO}_{3}$ was found at the field evaluation site than at the disease-suppressive sites, and significantly more $\mathrm{NH}_{4}$ was found at the field site than at sites $\mathrm{A}$ and $\mathrm{B}$ (Table 1). The three sites further differed from each other in $\mathrm{Fe}$ and $\mathrm{pH}\left(\mathrm{H}_{2} \mathrm{O}\right)$. The $\mathrm{pH}\left(\mathrm{H}_{2} \mathrm{O}\right)$ of field sites $\mathrm{B}$ and $\mathrm{C}$ was significantly lower than that of field site $\mathrm{A}$ and the trial site.

\section{Discussion}

The application of nonpathogenic F. oxysporum isolates to plant roots has shown promise for Fusarium wilt control in other crops $(1,22,28)$ and some success has been shown for banana as well $(20,35,53)$. The method of production of banana transplants lends itself to the introduction of biological control agents. Most commercial banana plantations are now being established with micropropagated plants that are disease and pest free. Once taken from in vitro culture, the rooted banana plantlets are transplanted into seedling trays, hardened off, and prepared for field planting. Therefore, biological control agents can be established on roots of micropropagated plants at any stage before field planting. Banana plantlets treated with nonpathogenic $F$. oxysporum endophytes before field planting have been shown to significantly increase the survival rate of Cavendish banana plants in nematode-infested fields in Costa Rica (40) and of Rasthali banana plants in $F$. oxysporum f. sp. cubense race 1-infested field in India (53). In our study, the nonpathogenic $F$. oxysporum isolates and $P$. fluorescens WCS 417 did not reduce banana wilt in the field, alone or in combination, but promising results were obtained with the greenhouse bioassay. These results are supported by similar findings from a study in Malaysia in which nonpathogenic F. oxysporum endophytes were unable to protect Pisang berangan banana against F. oxysporum f. sp. cubense race 4 in the field (54).

Greenhouse screening of candidate organisms, supported by robust field screening, is the only means to find nonpathogenic $F$. oxysporum isolates that can be considered as biological control agents. This method can be rewarding, because the well-known biological control isolate Fo47 was discovered this way in soils suppressive to Fusarium wilt of flax in Châteaurenard, France $(1,4)$. However, to optimally use nonpathogens for disease control, a good understanding of their mode of action is required (47). Nonpathogenic $F$. oxysporum strains can reduce disease incidence through competition for nutrients (4) or infection sites (45), and by inducing systemically acquired resistance in plants $(22,30)$. The nonpathogens used in the current study were all collected from banana roots in Kiepersol and are most likely well adapted to compete with the pathogen for nutrients such as carbon, nitrogen, and iron (12). At the endophyte collection sites, significantly less $\mathrm{K}$ and $\mathrm{Mg}$ and significantly more $\mathrm{NO}_{3}$ was found in soils than at the trial site. Higher $\mathrm{K}$ and $\mathrm{Mg}$ levels were associated with the suppression of $F$. oxysporum f. sp. cubense chlamydospore germination and less Fusarium wilt development of banana in greenhouse studies (38), and higher $\mathrm{NO}_{3}$ with decreased disease development of Fusarium wilt diseases (60). More noteworthy is the fact that the soil chemical components most often associated with Fusarium wiltsuppressive soils $\left(\mathrm{Ca}, \mathrm{NH}_{4}\right.$, and $\left.\mathrm{pH} ; 14,38,51,60\right)$ did not differ consistently between the endophyte collection sites and the trial site. Therefore, the distribution of these nutrients at the different sites does not explain the failure of the nonpathogenic $F$. oxysporum isolates to suppress disease development in the trial site.

The lack of field protection of Fusarium wilt of banana by nonpathogenic $F$. oxysporum endophytes in the current study could also be attributed to factors other than soil nutrition. These factors include competition with more established microorganisms in the rhizosphere (32), their mode of action and survival under field conditions (28), and the etiology of Fusarium wilt of Cavendish banana in the subtropics (56). Although nonpathogenic $F$. oxysporum and $P$. fluorescens are both known to induce resistance in plants against pathogens $(15,22,23,55)$, their mode of protection in banana against $F$. oxysporum f. sp. cubense first has to be determined to optimize application under field conditions. The establishment, survival, and competition of nonpathogenic $F$. oxysporum and WCS 417 with other soil microorganisms in the field, particularly in the subtropics under adverse environmental conditions, were not determined in the current study. In future, a marker would be used to separate the introduced organisms from indigenous

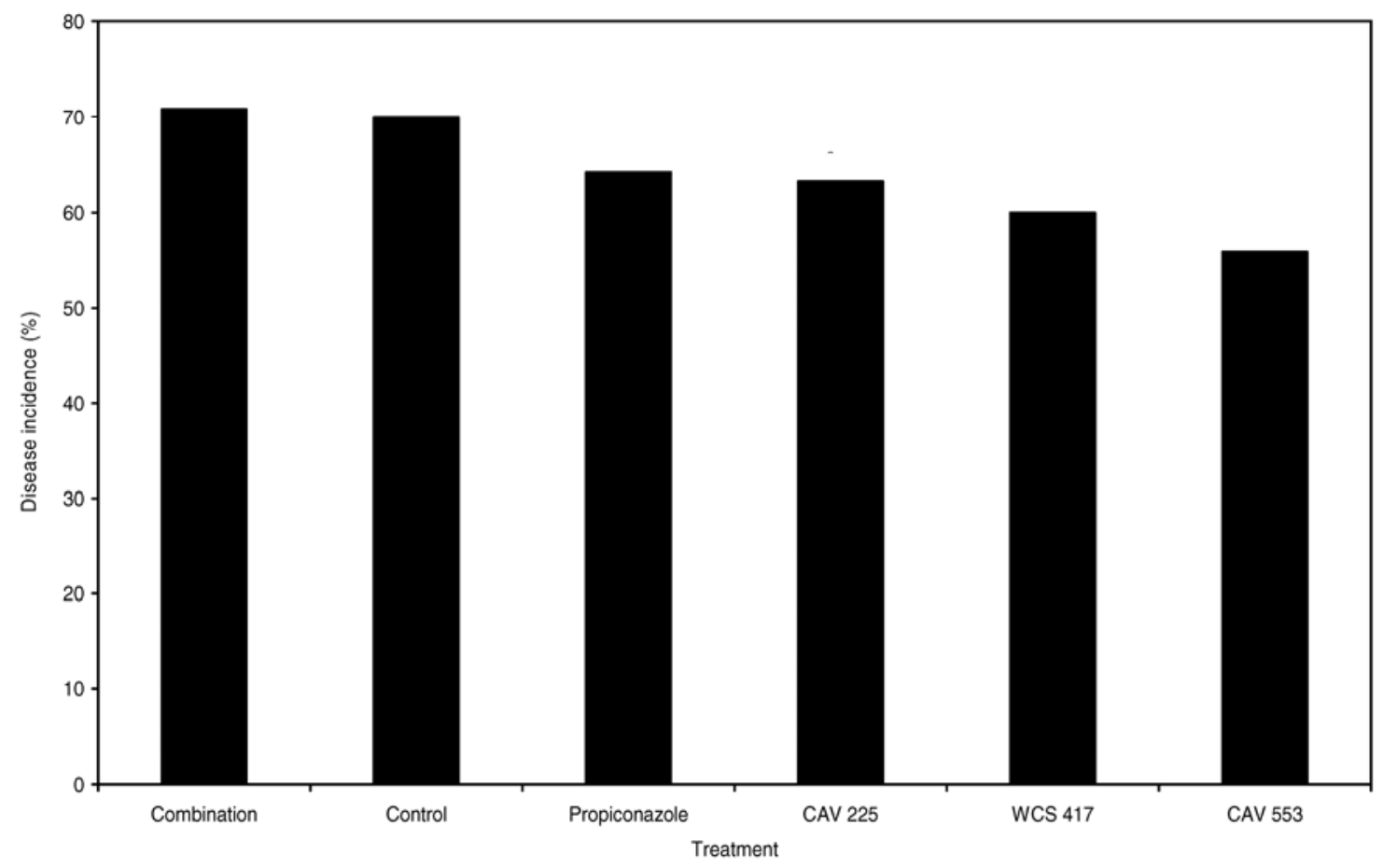

Fig. 2. Disease incidence of Fusarium wilt of banana caused by Fusarium oxysporum f. sp. cubense in the field following treatment with nonpathogenic $F$. oxysporum isolates CAV 225 and CAV 553, Pseudomonas fluorescens WCS 417, and a combination of CAV 255 + CAV $553+$ WCS 417. Control plants were either treated with the fungicide Propiconazole or were left untreated. Banana plants were grown in a field with the soil naturally infested with $F$. oxysporum f. sp. cubense. No significant differences were observed. 
strains in the soil and the root system of banana plants to further investigate their survival before new attempts are made to reconsider them as potential biocontrol agents. Also, more nonpathogenic $F$. oxysporum isolates will have to be included in field trials in an attempt to identify possible biological control candidates.

Other possible explanations for why the nonpathogenic $F$. oxysporum endophytes that significantly reduced the severity of Fusarium wilt of banana in the greenhouse were unable to protect banana plants against Fusarium wilt in the field when applied alone and in combination with WCS417 might involve the race of $F$. oxysporum f. sp. cubense, the banana cultivar involved, and the number of applications made. In their investigation, Thangavelu and Jayanthi (53) demonstrated that nonpathogenic $F$. oxysporum protected Rasthali banana against $F$. oxysporum f. sp. cubense race 1 in the field. However, nonpathogenic $F$. oxysporum was unable to protect Cavendish and Pisang berangan banana against $F$. oxysporum f. sp. cubense race 4 in the field (54). Based on the diversity in antagonistic activity we observed through a small set of 17 isolates of nonpathogenic $F$. oxysporum isolates originating from a limited area, it is possible that isolates from different geographical regions may provide different levels of disease reduction toward different races of $F$. oxysporum f. sp. cubense ( $F$. oxysporum f. sp. cubense race 4 in South Africa and F. oxysporum f. sp. cubense races 1 and 2 in India) when applied on different banana cultivars, as has been demonstrated for Fusarium wilts of other crops $(13,27,41)$. Thangavelu and Jayanthi (53) also reapplied the nonpathogen 2 and 4 months after field planting, which suggests that the inoculated nonpathogenic population can face obstacles to establish as biocontrol agents under field conditions (53).

The occurrence of healthy banana plants in Fusarium wilt-prone areas in South Africa suggests that the soils in which they were grown could have disease-suppressive properties. One could argue that the healthy banana plants might have escaped the disease or that they could be somaclonal variants resistant to Fusarium wilt (24). However, their association with nonpathogenic F. oxysporum endophytes that reduced Fusarium wilt significantly in greenhouse trials provides strong circumstantial evidence that the endophytes isolated from their roots have value as biocontrol organisms in the field. For instance, five isolates obtained from healthy banana in site C (including 553) reduced Fusarium wilt severity significantly. No $F$. oxysporum f. sp. cubense isolates were obtained from banana roots either at this site or at site A; the latter yielding endophytes with a poor ability to reduce Fusarium wilt in the greenhouse. Therefore, one could hypothesize that site A was not infested with F. oxysporum f. sp. cubense despite the presence of Fusarium wilt in close proximity to this site. The observation that banana roots colonized by nonpathogenic $F$. oxysporum isolates from sites B and $\mathrm{D}$ that significantly reduced disease incidence in the greenhouse were also colonized by $F$. oxysporum $\mathrm{f}$. sp. cubense deserves further analysis. One could also argue that the healthy plants were protected by the nonpathogens, despite root infection by the pathogen; or, conversely, that it was too early in the infection process by F. oxysporum f. sp. cubense for symptoms to have developed. Nevertheless, these plants were healthy under field conditions despite root infection by $F$. oxysporum f. sp. cubense, and the endophytes isolated from them were able to significantly reduce Fusarium wilt in greenhouse studies, which strongly suggests that they are candidates for field protection of banana plants against Fusarium wilt. Because nonpathogenic $F$. oxysporum endophytes from the three field sites sometimes grouped in the same IGS haplotypes, these haplotypes are either widely distributed or a great movement of haplotypes has occurred in the area. Another possibility is that banana root exudates might favor their selection (19,51).

The nonpathogenic F. oxysporum endophytes obtained from banana roots in Fusarium wilt-suppressive soils were highly diverse in both their PCR-RFLP profiles and their ability to reduce the effect of $F$. oxysporum f. sp. cubense in greenhouse trials. Between endophytes capable of reducing Fusarium wilt significantly in the greenhouse and those unable to limit the infectious activity of $F$. oxysporum f. sp. cubense isolate CAV 092, a number of endo- phytes produced a continuum of responses that were difficult to categorize as either truly suppressive or not; similar to what has been observed in the case of Fusarium wilt of flax (5). This suggests that the antagonistic activity of nonpathogenic $F$. oxysporum depends on mechanisms brought about by the regulation of several genes rather than a single gene; a finding that might complicate the development of markers for the rapid detection of nonpathogenic $F$. oxysporum strains with biological control properties.

The process of isolating and testing nonpathogenic F. oxysporum isolates for biological control is time and space consuming. If mass screening of nonpathogenic $F$. oxysporum isolates for biological control of Fusarium wilt diseases needs to be done, a screening technique that is more time and cost effective than pathogenicity testing needs to be developed. Such a technique might involve either the development of molecular markers for the screening of large numbers of candidate organisms or the use of an in vitro technique that is dependent on the mechanism of control. In studies by Nel et al. (35) and Thangavelu and Jayanthi (53), isolates of nonpathogenic $F$. oxysporum from the banana rhizosphere that suppressed Fusarium wilt most effectively in greenhouse trials were found to belong to the same PCR-RFLP haplotype group. However, this was not the case in the current study, where 10 nonpathogenic $F$. oxysporum isolates that reduced Fusarium wilt severity of banana significantly in the greenhouse were all placed in separate IGS haplotype groups, except for CAV 563 and CAV 565 that grouped together. Isolates that represented the same haplotype group but that were found in different soils-for example, CAV 531 (site A) and CAV 535 (site B)-also did not inhibit F. oxysporum $\mathrm{f}$. sp. cubense to the same degree. These findings support the hypothesis that factors additional to the isolates' phylogenetic relatedness, such as specific soil-strain interactions, may contribute to the fitness of individual isolates in soils to which they were introduced (11). The latter may further explain why, as yet, no molecular marker for the biocontrol activity of nonpathogenic $F$. oxysporum has been identified. It may also support the inclusion of more nonpathogenic F. oxysporum isolates as potential biocontrol candidates in future field evaluations.

The finding that the pathogenic isolates in the current study grouped together in one IGS haplotype group, and that all $F$. oxysporum f. sp. cubense isolates in South Africa represent a single VCG (57), entices one to believe that nonpathogenic $F$. oxysporum isolates with proper suppressiveness toward this clonal $F$. oxysporum $\mathrm{f}$. sp. cubense population could be of significant value in managing Fusarium wilt of banana in the country. These findings indicate that there is a real potential which needs to be exploited though two compatible strategies in an integrated pest management approach. The first one could be to stimulate the indigenous beneficial biota through conservation biological control methods, including the use of organic amendments (54), and the second one to inoculate and inundate biological control organisms into Fusarium wilt-susceptible banana plants. In both cases, however, the modes of action, the colonization of banana roots, the ecological fitness, and the survival in the field of the candidate microorganisms of interest first have to be determined.

\section{Acknowledgments}

We thank the Banana Growers Association of South Africa, the Technology and Human Resources of Industry Programme, and The National Research Foundation for financial assistance, DuRoi Laboratories for providing plants; B. Nel (Forestry and Agricultural Biotechnology Institute [FABI], University of Pretoria, South Africa) for technical assistance and advice; and personnel at FABI and the banana growers in Kiepersol for their assistance during the field trial.

\section{Literature Cited}

1. Alabouvette, C. 1986. Fusarium-wilt suppressive soils from the Châteaunard region: review of 10-years study. Agronomie 6:273-284.

2. Alabouvette, C. 1990. Biological control of Fusarium wilt pathogens in suppressive soils. Pages 27-43 in: Biological Control of Soil-Borne Plant Pathogens. D. Hornby, ed. CAB International, Wallingford, UK.

3. Alabouvette, C., Backhouse, D., Steinberg, C., Donovan, N. J., EdelHermann, V., and Burgess, L. W. 2004. Microbial diversity in soil-effects 
on crop health. Pages 121-138 in: Managing Soil Quality: Challenges in Modern Agriculture. P. Schjonning, S. Elmholt, and B. T. Christensen, eds. CAB International, Wallingford, UK.

4. Alabouvette, C., and Couteaudier, Y. 1992. Biological control of Fusarium wilts with nonpathogenic Fusaria. Pages 414-415 in: Biological Control of Plant Diseases: Progress and Challenges for the Future. E. C. Tjamos, G. C. Papavizas, and R. J. Cook, eds. Plenum Press, New York.

5. Alabouvette, C., Olivain, C., Migheli, Q., and Steinberg, C. 2009. Microbiological control of soil-borne phytopathogenic fungi with special emphasis on wilt-inducing Fusarium oxysporum. New Phytol. 184:529-544.

6. Appel, D. J., and Gordon, T. R. 1995. Intraspecific variation within the population of Fusarium oxysporum based on RFLP analysis of the intergenic spacer region of the rDNA. Exp. Mycol. 19:120-128.

7. Armstrong, G. M., and Armstrong, J. K. 1981. Formae speciales and races of Fusarium oxysporum causing wilt diseases. Pages 391-399 in: Fusarium: Disease, Biology and Taxonomy. P. E. Nelson, T. A. Toussoun, and R. J. Cook, eds. Pennsylvania State University Press, University Park.

8. Baayen, R. P., O’Donnell, K., Bonants, P. J. M., Cigelnik, E., Kroon, L. P. N. M., Roebroeck, E. J. A., and Waalwijk, C. 2000. Gene genealogies and AFLP analyses in the Fusarium oxysporum complex identify monophyletic and nonmonophyletic formae speciales causing wilt and rot disease. Phytopathology 90:891-900.

9. Booth, C. 1977. Fusarium. Laboratory Guide to the Identification of the Major Species. Commonwealth. Mycological Institute, Kew, Surrey, England.

10. Carlier, J., De Waele, D., and Escalant, J. V. 2002. Global evaluation of Musa germplasm for resistance to Fusarium wilt, Mycosphaerella leaf spot diseases and nematodes. INIBAP Technical Guidelines 6. INIBAP Publications, Montpellier, France.

11. Corman, A., Couteaudier, Y., Zegerman, M., and Alabouvette, C. 1986. Réceptivité des sols aux fusarioses vasculaires: méthode statistique d'analyse des résultats. Agronomie 6:751-757.

12. Couteaudier, Y., and Alabouvette, C. 1990. Quantitative comparison of Fusarium oxysporum competitiveness in relation with carbon utilization. FEMS Microbiol. Ecol. 74:261-268.

13. Davis, R. D., Moore, N. Y., and Kochman, J. K. 1996. Characterisation of a population of Fusarium oxysporum $\mathrm{f}$. sp. vasinfectum causing wilt of cotton in Australia. Aust. J. Agric. Res. 47:1143-1156.

14. Domínguez, J., Negrín, M. A., and Rodríguez, C. M. 2001. Aggregate water-stability, particle size and soil solution properties in conducive and suppressive soils to Fusarium wilt of banana from Canary Islands. Soil Biol. Biochem. 33:449-455.

15. Duijff, B. J., Pouhair, D., Olivain, C., Alabouvette, C., and Lemanceau, P. 1998. Implication of systemic induced resistance in the suppression of Fusarium wilt of tomato by Pseudomonas fluorescens WSC417 $\mathrm{r}$ and by non-pathogenic Fusarium oxysporum Fo47. Eur. J. Plant. Pathol. 104:903910.

16. Duijff, B. J., Recorbet, G. Bakker, P. A. H., Loper, J. E., and Lemanceau, P. 1999. Microbial antagonism at the root level is involved in the suppression of Fusarium wilt by the combination of non-pathogenic Fusarium oxysporum Fo47 and Pseudomonas putida WCS358. Phytopathology 89:1073-1079.

17. Edel, V., Steinberg, C., Avelange, I., Laguerre, G., and Alabouvette, C. 1995. Comparison of three molecular methods for the characterization of Fusarium oxysporum strains. Phytopathology 85:579-585.

18. Edel, V., Steinberg, C., Gautheron, N., and Alabouvette, C. 1997. Evaluation of restriction analysis of polymerase chain reaction (PCR)-amplified ribosomal DNA for the identification of Fusarium species. Mycol. Res. 101:179-187.

19. Edel, V., Steinberg, C., Gautheron, N., and Alabouvette, C. 1997. Populations of non-pathogenic Fusarium oxysporum associated with roots of four plant species compared to soilborne populations. Phytopathology 87:693697.

20. Forsyth, L. M., Smith, L. J., and Aitken, E. A. B. 2006. Identification and characterization of non-pathogenic Fusarium oxysporum capable of increasing and decreasing Fusarium wilt severity. Mycol. Res. 110:929-935.

21. Fourie, G., Steenkamp, E. T., Gordon, T. R., and Viljoen, A. 2009. Evolutionary relationships among the Fusarium oxysporum f. sp. cubense vegetative compatibility groups. Appl. Environ. Microbiol. 75:4770-4781

22. Fuchs, J. G., Moënne-Loccoz, Y., and Défago, G. 1997. Nonpathogenic Fusarium oxysporum strain Fo47 induces resistance to Fusarium wilt in tomato. Plant Dis. 81:492-496.

23. Gerlach, K. S., Bentley S., Aitken E. A. B., Moore N. Y., and Pegg, K. G. 1999. Investigation of non-pathogenic strains of Fusarium oxysporum for the suppression of Fusarium wilt of banana in Australia. Page 28 in: Second International Fusarium Workshop. C. Alabouvette, ed. INRA-CMSE, Dijon, France.

24. Hwang, S. C. 1999. Recent development on Fusarium R\&D of banana in Taiwan. Pages 39-49 in: Banana Fusarium Wilt Management: Towards Sustainable Cultivation. Proc. Int. Workshop Banana Fusarium Wilt Disease. A. B. Molina, N. H. N. Masdek, and K. W. Liew, eds. Genting Highlands Resort, Malaysia.

25. King, E. O., Ward, M. K., and Raney, D. E. 1954. Two simple media for the demonstration of phycocyanin and fluorescin. J. Lab. Clin.
Med. 44:301-307.

26. Komada, H. 1975. Development of a selective medium for quantitative isolation of Fusarium oxysporum from natural soil. Rev. Plant Prot. Res. $8: 115-125$.

27. Landa, B. B., Navas-Cortés. J. A., Hervás, A., and Jiménez-Díaz, R. M. 2001. Influence of temperature and inoculum density of Fusarium oxysporum f. sp. ciceris on suppression of Fusarium wilt of chickpea by rhizosphere bacteria. Phytopathology 91:807-816.

28. Larkin, R. P., and Fravel, D. R. 1998. Efficacy of various fungal and bacterial biocontrol organisms for the control of Fusarium wilt of tomato. Plant Dis. 82:1018-1022.

29. Larkin, R. P., and Fravel, D. R. 2002. Effects of varying environmental conditions on biological control of Fusarium wilt of tomato by non-pathogenic Fusarium spp. Phytopathology 92:1162-1166.

30. Leeman, M., den Ouden, F. M., Van Pelt, J. A., Cornelissen, C., MatamalaGarros, A., Bakker, P. A. H. M., and Schippers, B. 1996. Suppression of Fusarium wilt of radish by co-inoculation of fluorescent Pseudomonas spp. and root-colonizing fungi. Eur. J. Plant. Pathol. 102:21-31.

31. Louvet, J., Alabouvette, C., and Rouxel, F. 1981. Microbiological suppressiveness of some soils to Fusarium wilts. Pages 260-275 in: Fusarium: Diseases, Biology, and Taxonomy. P. E. Nelson, T. A. Toussoun, and R. J. Cook, eds. Pennsylvania State University Press, University Park.

32. Lugtenberg, B. J. J., and Dekkers, L. C. 1999. What make Pseudomonas bacteria rhizosphere competent? Environ. Microbiol. 1:9-13.

33. Mishra, P. K., Fox, R. T. V., and Culham, A. 2002. Development of a PCRbased assay for rapid identification of pathogenic Fusaria. FEMS Microbiol. Lett. 10793:1-4

34. Nel, B., Steinberg, C., Labuschagne, N., and Viljoen, A. 2006. Isolation and characterization of non-pathogenic Fusarium oxysporum isolates from the rhizosphere of healthy banana plants. Plant Pathol. 55:207-216.

35. Nel, B., Steinberg, C., Labuschagne, N., and Viljoen, A. 2006. The potential of non-pathogenic Fusarium oxysporum and other biological control organisms for suppressing Fusarium wilt of banana. Plant Pathol. 55:217-223.

36. Nel, B., Steinberg, N., Labuschagne, N., and Viljoen, A. 2007. Evaluation of fungicides and sterilants for the potential application in the management of Fusarium wilt of banana. Crop Prot. 26:697-705

37. Nelson, P. E., Toussoun, T. A., and Marasas, W. F. O. 1983. Fusarium Species: An illustrated Manual for Identification. The Pennsylvania State University Press, , University Park.

38. Peng, H. X., Sivasithamparam, K., and Turner, D. W. 1999. Chlamydospore germination and Fusarium wilt of banana plantlets in suppressive and conducive soils are affected by physical and chemical factors. Soil Biol. Biochem. 31:1363-1374.

39. Ploetz, R. C. 2005. Panama disease, an old enemy rears its ugly head: parts 1 and 2. In: Plant Health Progress, APSnet. Online publication. doi:10.1094/PHP-2005-1221-01-RV.

40. Pocasangre, L., Sikora, R. A., Vilich, V., and Schuster, R. P. 1999. Survey of endophytic fungi from Central America and screening for biological control of the burrowing nematode (Radopholus similis) Acta. Hortic. 531:283-289.

41. Postma, J., and Rattink, H. 1992. Biological control of Fusarium wilt of carnation with a non-pathogenic isolate of Fusarium oxysporum. Can. J. Bot. 70:1199-1205

42. Raaijmakers, J. M., Van der Sluis, I., Koster, M., Bakker, P. A. H. M., Weisbeek, P. J., and Schippers, B. 1995. Utilization of heterologous siderophores and rhizosphere competence of fluorescent Pseudomonas spp. Can. J. Microbiol. 41:126-135.

43. Sambrook, J., Fritsch, E. F., and Maniatis, T. 1989. Molecular Cloning: A Laboratory Manual, 2nd ed. Cold Spring Harbor Laboratory Press, Cold Spring Harbor, NY. Pages E.3-E.4.

44. Scher, M., and Baker, R. 1982. Mechanism of biological control in a Fusarium-suppressive soil. Phytopathology 70:412-417

45. Schneider, R. W. 1984. Effects of non-pathogenic strains of Fusarium ox ysporum on celery root infection by Fusarium oxysporum f. sp. apii and a novel use of lineweaver-burk double reciprocal plot technique. Phytopathology 74:646-653.

46. Sikora, R. A., Schuster, R. P., and Griesbach, M. 2000. Improved plant health through biological enhancement of banana planting material with mutualistic endophytes. Acta. Hortic. 540:409-413.

47. Sneh, B. 1998. Use of non-pathogenic or hypovirulent fungal strains to protect plants against closely related fungal pathogens. Biotechnol. Adv. $16: 1-32$.

48. Steinberg, C., Edel-Hermann, V., Alabouvette, C., and Lemanceau, P. 2007 Soil suppressiveness to plant diseases. Pages 455-478 in: Modern Soil Microbiology. J. van Elsas, J. Jansson, and J. T. Trevors, eds. CRC Press, New York.

49. Strauss, J., and Labuschagne, N. 1995. Pathogenicity of Fusarium solani isolates on citrus roots and evaluation of different inoculum types. Toegepaste Plantwetenskap 9:48-52.

50. Stover, R. H. 1962. Fusarial Wilt (Panama Disease) of Bananas and Other Musa Species. Commonwealth Mycological Institute, Kew, UK.

51. Stover, R. H., Hildreth, R. C., and Thorton, N. C. 1961. Studies on Fusarium wilt of bananas. VII. Field control. Can. J. Bot. 39:197-206.

52. Termorshuizen, A. J., Van Rijn, E., Van der Gaag, D. J., Alabouvette, C., Chen, Y., Lagerlöf, J., Malandrakis, A. A., Paplomatas, E. J., Rämert, B., 
Ryckeboer, J., Steinberg, C., and Zmora-Nahum, S. 2006. Suppressiveness of 18 composts against 7 soilborne plant pathogens. Soil Biol. Biochem. 38:2461-2477.

53. Thangavelu, R., and Jayanthi, A. 2009. RFLP analysis of rDNA-ITS regions of native non-pathogenic Fusarium oxysporum isolates and their field evaluation for the suppression of Fusarium wilt disease of banana. Australas. Plant Pathol. 38:13-21.

54. Ting, A. S. Y., Sariah, M., Kadir, J., and Gurmit, S. 2009. Field evaluation of non-pathogenic Fusarium oxysporum isolates upm31p1 and upm39b3 for the control of Fusarium wilt in 'Pisang berangan' (Musa, AAA). Acta. Hortic. 828:139-144.

55. Van Peer, R., Niemann, G. J., and Schippers, B. 1991. Induced resistance and phytoalexin accumulation in biological control of carnation by Pseudomonas spp. strain WCS 417r. Phytopathology 81:728-734
56. Viljoen, A. 2002. The status of Fusarium wilt (Panama disease) of banana in South Africa. S. Afr. J. Sci. 98:341-344.

57. Visser, M., Gordon, T. R., Fourie, G., and Viljoen, A. 2010. Characterization of South African isolates of Fusarium oxysporum f. sp cubense from Cavendish banana. S. Afr. J. Sci. 106:44-49.

58. Weller, D. M., Raaijmakers, J. M., McSpadden-Gardener, B. B., and Thomashow, L. S. 2002. Microbial populations responsible for specific soil suppressiveness to plant pathogens. Annu. Rev. Phytopathol. 40:309-348.

59. Whipps, J. M. 2001. Microbial interactions and biocontrol in the rhizosphere. J. Exp. Bot. 52:487-511.

60. Woltz, S. S., and Jones, J. P. 1981. Nutritional requirements of Fusarium oxysporum: basis for a disease control system. Pages 340-349 in Fusarium: Diseases, Biology, and Taxonomy. P. E. Nelson, T. A. Toussoun, and R. J. Cook, eds. Pennsylvania State University Press, University Park. 